C. ZHANG,* J.-J. WANG, Y. LIU, H. MA, X.-L. YANG, H.-B. XU (HUAZHONG UNIVERSITY OF SCIENCE AND TECHNOLOGY, WUHAN, P. R. OF CHINA)

Main-Chain Organometallic Microporous Polymers Based on Triptycene: Synthesis and Catalytic Application in the Suzuki-Miyaura Coupling Reaction

Chem. Eur. J. 2013, 19, 5004-5008.

\section{Suzuki-Miyaura Coupling with Main-Chain Organometallic Polymer}

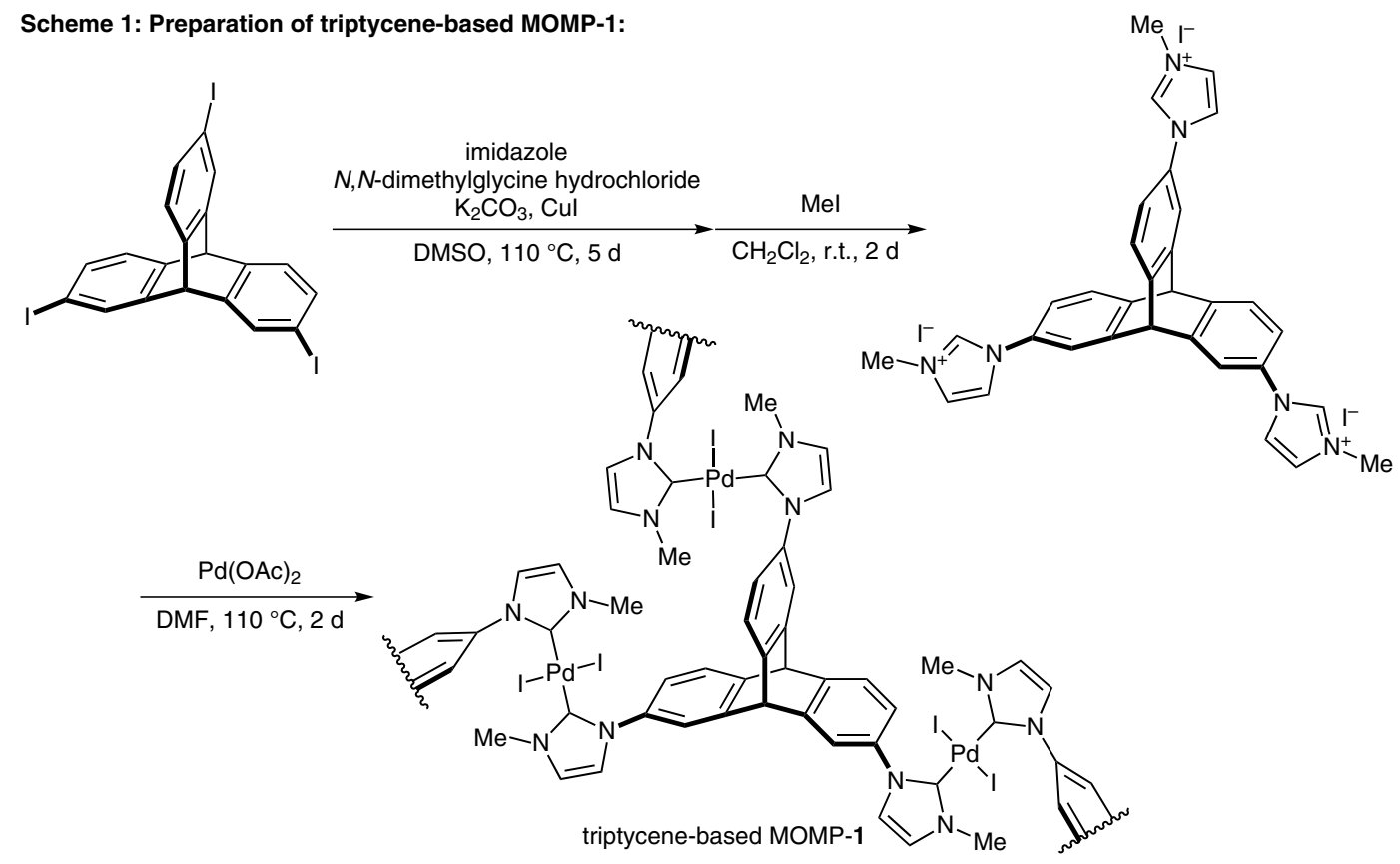

Scheme 2: Suzuki-Miyaura coupling catalyzed by MOMP-1:<smiles>[R]c1ccc([X])cc1</smiles>

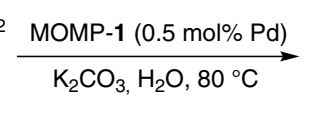
$\mathrm{R}=\mathrm{OMe}, \mathrm{X}=\mathrm{I} ; 95 \%$ yield $\mathrm{R}=\mathrm{NO}_{2}, \mathrm{X}=\mathrm{Br} ; 95 \%$ yield $\mathrm{R}=\mathrm{H}, \mathrm{X}=\mathrm{Br} ; 97 \%$ yield $\mathrm{R}=\mathrm{OMe}, \mathrm{X}=\mathrm{Br} ; 93 \%$ yield $\mathrm{R}=\mathrm{NO}_{2}, \mathrm{X}=\mathrm{Cl} ; 94 \%$ yield $\mathrm{R}=\mathrm{H}, \mathrm{X}=\mathrm{Cl} ; 92 \%$ yield $\mathrm{R}=\mathrm{OMe}, \mathrm{X}=\mathrm{Cl} ; 88 \%$ yield $\mathrm{R}=\mathrm{Me}, \mathrm{X}=\mathrm{Cl} ; 90 \%$ yield

\section{Category}

Polymer-Supported

Synthesis

Key words

main-chain organometallic polymers

palladium

Suzuki-Miyaura coupling

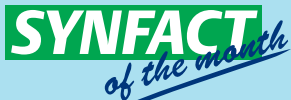

Significance: A triptycene-based NHC-Pd mainchain organometallic microporous polymer (MOMP-1) was prepared from 2,6,14-triiodotriptycene according to Scheme 1. MOMP-1 catalyzed the Suzuki-Miyaura coupling of aryl halides with phenylboronic acid in water to give the corresponding biaryls in 88-97\% yield (Scheme 2, 9 examples).
Comment: The characterization of MOMP-1 was performed by NMR, SEM, TEM, EDS, XRPD, TGA, nitrogen sorption, and elemental analyses. In the coupling of bromobenzene with phenylboronic acid, the catalyst was recovered by filtration and reused twice without loss of its catalytic activity $\left(2^{\text {nd }}\right.$ run: $96 \%$ yield, $3^{\text {rd }}$ run: $96 \%$ yield).

SYNFACTS Contributors: Yasuhiro Uozumi, Aya Tazawa 